\title{
Avaliação na educação infantil: contribuições a luz da pedagogia histórico- crítica e da psicologia histórico cultural
}

\author{
Tainara Pereira Castro ${ }^{1}$ \\ Ana Carolina Galvão
}

\begin{abstract}
Resumo
Este artigo é parte de um estudo de mestrado que objetivou contribuir com discussões no âmbito da avaliação na educação infantil à luz da pedagogia histórico-crítica, sinalizando elementos que possibilitem compreender a avaliação da aprendizagem como atividade mediadora entre o ensino e a aprendizagem. Buscamos no materialismo histórico-dialético os fundamentos para demarcar nosso embate com as teorias limitadas a compreender o real em sua aparência fenomênica. Organizamos este texto em dois momentos que se articulam, sendo: explicitar as relações entre ensino, aprendizagem e desenvolvimento; conceituar como a avaliação da aprendizagem se situa nesta dinâmica, para relacioná-la ao âmbito da prática pedagógica.
\end{abstract}

Palavras-Chave: Avaliação na educação infantil, pedagogia histórico-crítica, psicologia histórico-cultural.

\section{Assessment in early childhood education: contributions in the light of historical-critical pedagogy and historical-cultural psychology}

\begin{abstract}
This paper is part of a master's study that aimed to contribute with discussions in the scope of assessment in early childhood education in the light of historical-critical pedagogy, indicating elements that enable to understand the assessment of learning as a mediating activity between teaching and learning. We sought in historical-dialectical materialism the foundations to demarcate our confrontations with theories limited to understanding the real in its phenomenal appearance. We organized the text in two moments which are articulated, namely: to clarify the relations between teaching, learning and development and to conceptualize how the assessment of learning is situated in this dynamics, in order to relate it to the scope of pedagogical practice.
\end{abstract}

Keywords: Assessment in early childhood education, historical-critical pedagogy, historical-cultural psychology.

\footnotetext{
${ }^{1}$ Graduada em Pedagogia pela Universidade do Estado da Bahia. Mestre e Doutoranda pelo Programa de PósGraduação em Educação da Universidade Federal do Espírito Santo. Professora da Educação Infantil do município de Serra-ES. Membro do grupo de pesquisa "Pedagogia histórico crítica e educação escolar". Orcid: https://orcid.org/0000-0002-8864-8463. Email: naracastro19@ hotmail.com.

${ }^{2}$ Graduada em Pedagogia pela Unesp/Bauru e Doutora em Educação Escolar pela Unesp/Araraquara. Professora do Departamento de Teorias do Ensino e Práticas Educacionais e do Programa de Pós-graduação em Educação da Universidade Federal do Espírito Santo, membro do Núcleo de Educação Infantil (Nedi-Ufes) e líder do grupo de pesquisa "Pedagogia histórico crítica e educação escolar". Orcid: https://orcid.org/0000-0001-84518269. Email: galvao.marsiglia@gmail.com.
} 


\section{Introdução}

Compreendendo que a educação infantil deve ter o ensino como eixo para a organização do trabalho pedagógico e a necessidade de organização intencional das ações pedagógicas, a pedagogia histórico-crítica assume um posicionamento contrário às concepções pedagógicas que desqualificam a escola e o ensino e considera a escola um espaço essencial para a formação da individualidade humana e o papel do professor de extrema importância para esse processo. Tomando como fundamento teórico-metodológico o materialismo histórico-dialético, compreendemos que tal perspectiva pedagógica nos oferece as reais possibilidades para a compreensão da realidade como síntese de determinações múltiplas, pela mediação da abstração (teoria).

Entendemos que conhecer implica reconhecer as relações que interpenetram os fenômenos e tal processo não se dá de forma direta. No estudo que realizamos no mestrado (CASTRO, 2017), nosso esforço foi o de situar a predominância dos estudos na área da avaliação na educação infantil, para com isso, , identificar seus elementos estruturantes, como eles se relacionam no âmbito da prática educativa e a partir deste movimento, apreender suas possibilidades. Notamos, no levantamento feito nas produções da Biblioteca Digital de Teses e Dissertações (BDTD), nos documentos que subsidiam a educação infantil na atualidade, que as discussões hegemônicas em torno da educação infantil saem em defesa de uma pedagogia da infância que atende ao que mencionamos sobre a desqualificação da escola como espaço formativo intencional. À luz dos nossos referenciais, identificamos que esta concepção traz consigo, de modo implícito, uma crescente fetichização da infância, que acaba por descaracterizar a criança como sujeito histórico, conduzindo cada vez mais os sujeitos à adaptação a uma sociedade desigual, pois secundariza-se a necessidade da transmissão da cultura.

Em contrapartida, compreendendo que a natureza humana não é dada aos indivíduos e sim produzida coletiva e socialmente à medida que os indivíduos se apropriam da humanidade objetivada, a pedagogia histórico-crítica e a psicologia histórico-cultural posicionam-se contrárias a essa perspectiva teórica hegemônica e oferecem contribuições imprescindíveis para a compreensão da atuação docente, como também para compreensão da avaliação na educação infantil como eixo fundamental para a organização do trabalho 
pedagógico. Tratando especificamente da avaliação da aprendizagem no âmbito da pedagogia histórico-crítica, podemos tomá-la como uma atividade mediadora no interior da prática educativa, que se interpõe entre a atividade de ensino, específica do professor, e a atividade de aprendizagem, específica do aluno.

No esforço de contribuir de forma propositiva com discussões no âmbito do objeto deste estudo, sinalizaremos elementos que nos permitirão compreender a avaliação da aprendizagem como atividade mediadora entre a atividade de ensino e a atividade de aprendizagem. Para tanto, retomaremos, os fundamentos da pedagogia histórico-crítica e da psicologia histórico-cultural, que serão explicitados ao longo deste texto. Organizamos este texto em dois momentos que se articulam. Primeiramente procuraremos explicitar as relações entre ensino, aprendizagem e desenvolvimento e conceituar como a avaliação da aprendizagem se situa nesta dinâmica, para relacioná-la ao âmbito da prática pedagógica.

Relações entre a atividade de ensino, atividade de aprendizagem e avaliação da aprendizagem

Compreendendo que a natureza humana é produzida histórica e socialmente pelo conjunto da humanidade, tanto a pedagogia histórico-crítica quanto a psicologia históricocultural destacam duas condições para que esta se consolide: primeiro, é preciso entender que é pela atividade do sujeito que os elementos da cultura tornam-se parte de sua individualidade e segundo, que a apropriação é resultado de um processo mediado por outros sujeitos que transmitem às novas gerações os elementos da cultura, sendo, portanto, um processo educativo.

$\mathrm{Na}$ atualidade, a escola constitui-se como o espaço institucionalizado para a socialização do saber sistematizado, saber este oriundo de esferas filosóficas, artísticas, científicas. Ocorre que em uma sociedade marcada pelas relações de classe, a escola reserva aos diferentes sujeitos, possibilidades distintas de humanização. Nossa defesa é a de que a escola oportunize a apropriação dos conhecimentos a todos os indivíduos.

Se a escola é um espaço em que a educação encontra lugar, resta-nos discutir a especificidade no trato com aquilo que lhe é objeto: o saber sistematizado, as formas mais adequadas a sua sistematização, bem como o sujeito ao qual se destina. Para compreender a 
concretude da escola, implica então pensá-la a partir da tríade conteúdo-forma-destinatário (MARTINS, 2013).

No que se refere ao conteúdo, a pedagogia histórico-crítica indica a necessidade de a educação escolar orientar-se pelo conceito de clássico. Saviani (2013, p. 13) afirma que "[...] o clássico é aquilo que se firmou como fundamental, como essencial", é aquilo que "[...] resistiu ao tempo" (SAVIANI, 2013, p. 17. Assim, o clássico diz respeito aos conteúdos que ao longo do tempo se mostraram historicamente necessários para a efetiva relação do sujeito com a realidade, sendo, portanto, relevante para o desenvolvimento das próximas gerações, bem como do indivíduo. Deste modo, dois critérios devem orientar sua identificação: o caráter histórico dos conhecimentos, bem como a sua possibilidade de explicar a realidade.

Ao pensar a seleção dos conteúdos a partir do critério de clássico, há que organizá-lo de maneira que seja possível sua transmissão aos outros. É necessário, assim a organização das formas mais adequadas para atingir esta finalidade (espaço, tempo, procedimentos etc.) para que, progressivamente, "[...] cada indivíduo singular realize, na forma de segunda natureza, a humanidade produzida historicamente" (SAVIANI, 2013, p. 13). Pensar o conteúdo e as formas mais adequadas para sua sistematização requer também considerar o sujeito a quem se destina o ato educativo. Martins (2013, p. 297) destaca que este é "[...] entendido, nesta perspectiva, como alguém que sintetiza, a cada período da vida, a história das apropriações que lhe foram legadas". Fazendo a relação entre esses três elementos, o conteúdo que se quer transmitir requer a organização de formas específicas que sejam favoráveis à sua apropriação. Destarte, para que selecionemos os conteúdos, há que se identificar quais as possibilidades de sua apropriação por um determinado sujeito, o que impõe conhecer o destinatário, para assim traçar as relações que se estabelecerão entre eles.

Para tanto, é preciso compreender o estado real de desenvolvimento do indivíduo; identificar o lugar que ocupa nas relações sociais. Leontiev (2006, p. 63) destaca que "[...] esse lugar, em si mesmo, não determina o desenvolvimento: ele simplesmente caracteriza o estágio existente já alcançado”. Ao passo que se compreende a criança, que relações ela estabelece com a realidade, é possível identificar quais conteúdos irão possibilitar a promoção de seu desenvolvimento, especificamente, o que ensinar e quais encaminhamentos metodológicos serão necessários para atingir esta finalidade. Ocorre que, para conseguir 
identificar as formas mais adequadas de transmissão do conhecimento, há que se ter clareza sobre o conteúdo de ensino, de forma a organizá-lo de forma sequencial e sistemática numa ação pedagógica, sendo necessária a observação constante se o que se propõe a ensinar está sendo dominado pela criança, constituindo-se uma conquista em seu desenvolvimento.

Assumindo que o trabalho educativo é uma atividade quem tem como finalidade a constituição de uma segunda natureza, implica-nos reconhecer sua especificidade, como ela se materializa e suas relações com a avaliação da aprendizagem. Nesse intento, o trato que dispensaremos à especificidade de cada atividade (ensino e aprendizagem) é apenas uma maneira de sistematizar o lugar de cada uma no interior da prática educativa, mas sublinhamos desde já que elas se imbricam. Entendemos que o núcleo central da atividade de ensino, vincula-se ao trabalho do professor; a atividade de aprendizagem constitui-se como nuclear do aluno e a avaliação da aprendizagem ultrapassa a relação entre cada polo (professor-aluno), interpõe-se entre ambos e realiza mudanças qualitativas nesta relação.

No ensino, temos o professor como sujeito desta atividade, que possui como finalidade possibilitar a humanização dos indivíduos por meio das ações de que forem encaminhadas por sua atividade. Assim, coadunando com o pensamento de Martins (2016, p. 18) “[...] as ações de ensino desenvolventes não são aquelas que meramente reproduzem a vida cotidiana em seu funcionamento tipicamente espontâneo, assistemático, mas aquelas que requerem e ao mesmo tempo promovem a complexificação das funções psíquicas".

Nessa direção, Vigotski (2006, p. 114) destaca que “[...] o único bom ensino é o que se adianta ao desenvolvimento". Com tal afirmação, temos a defesa, portanto, de que o ensino é fonte de desenvolvimento, uma vez que a formação de novas capacidades do psiquismo depende das mediações que serão oportunizadas à criança. Ao defender o ensino na educação infantil e sinalizando que este produz mudanças significativas no pensamento da criança, estamos presumindo uma determinada relação que considera os processos de ensino como favorecedores do desenvolvimento infantil. À medida que o ensino se constitui como processo que se materializa no nível interpsíquico, encaminha também conquistas ao nível intrapsíquico da criança. Na defesa da atividade de ensino a ser realizada pelo professor, Moraes (2008, p. 102) evidencia que esta 
[...] constitui-se o núcleo do trabalho do professor no processo de humanização dos escolares. O que mobiliza os professores estarem em atividade de ensino é a necessidade de organizar suas intervenções pedagógicas - o ensino, o qual, se adequadamente organizado, possibilitará a aprendizagem dos escolares e, consequentemente, proporcionará seu desenvolvimento psicológico, isto é, uma transformação do sujeito no movimento de apropriação dos conhecimentos teóricos.

As ações suscitadas pelo professor devem possibilitar necessidades de aprendizagem para os estudantes. A atividade de aprendizagem caracteriza-se como a possibilidade de o aluno apropriar-se dos conhecimentos e desenvolver suas funções psíquicas. De acordo com Vigotski (2006), a aprendizagem é um momento importante no desenvolvimento da criança, possibilitando-a adquirir as características humanas que se formaram historicamente. Destaca ainda o autor que

[...] a aprendizagem não é, em si mesma, desenvolvimento, mas uma correta organização da aprendizagem da criança conduz o desenvolvimento mental, ativa todo um grupo de processos de desenvolvimento, e esta ativação não poderia produzir-se sem a aprendizagem (VIGOTSKI, 2006, p. 115).

Isso significa que por meio do ensino, que se desencadeia em situações de aprendizagem, é que se dá o desenvolvimento da criança, ou seja, o processo de desenvolvimento não coincide com a aprendizagem, mas o antecede para promovê-lo.

O ensino não deve se limitar a desenvolver aquilo que já se consolidou na criança como conquista para seu psiquismo, mas é preciso avançar, colocar em movimento aquilo que ainda está em iminência em seu desenvolvimento. Desta maneira, a relação entre ensino e aprendizagem institui-se como possibilidade de avançar o desenvolvimento das funções psíquicas que se encontram na zona de desenvolvimento iminente da criança. $\mathrm{O}$ desafio para a atividade do professor é identificar aquilo que já está constituído na criança e aquilo que ainda está se formando.

Em síntese, no que se refere à atividade de ensino, torna-se pertinente compreender a especificidade daquilo que lhe é objeto: os conhecimentos teóricos convertidos em saber escolar. Para tanto, torna-se importante organizar as ações e operações para que a atividade se efetive. No âmbito da atividade de aprendizagem, é importante que as ações realizadas pelo professor produzam necessidades de apropriação dos conhecimentos. O objeto da aprendizagem tem a ver com a transformação da relação do sujeito com a realidade. Ao passo 
que as finalidades da atividade coincidem com o objeto dela, desencadeiam-se os motivos, bem como as formas para a concretização da aprendizagem.

Estabelecendo as relações entre ensino, avaliação e aprendizagem, assinalamos que a avaliação se constitui como atividade mediadora no interior da prática educativa, o que significa entendê-la como movimento da atividade que se interpõe sobre os polos do ensino e da aprendizagem, captando suas relações e as ultrapassando, promovendo a transformação de todo o conjunto (MARTINS, 2013).

Moraes (2008, p. 108) destaca que "[...] o objetivo principal da avaliação consiste na reflexão das ações desenvolvidas tanto pelo aluno como pelo professor, no sentido de qualificar o processo de atividade cognitiva dos envolvidos". Além de possibilitar ao professor acompanhar se a atividade de ensino desencadeou ou não atividades de aprendizagem, a avaliação como atividade mediadora oferece elementos para a reorganização de toda atividade educativa. Acresce ainda a autora que

[...] no processo avaliativo, é importante observar se os objetivos de realização das atividades propostas pelo professor constituem propostas significativas para o aluno. Se os alunos não realizam a atividade com base em uma necessidade própria, de acordo com seus motivos, esta não pode ser considerada atividade [...] o professor necessita saber o significado social do que se ensina para que este ensino possa ter sentido para a criança (MORAES, 2008, p. 109).

Tal excerto chama a atenção para que o professor, além de compreender o desenvolvimento da criança, entender também teoricamente o movimento do objeto de sua atividade, de modo que organize o percurso para a apropriação do conteúdo, não cair em uma prática que entenda que importa suprir imediatamente as necessidades da criança tendo em vista a formação de significado sobre o conhecimento ao nível da cotidianeidade. O significado social do objeto da atividade do professor deve se ater aos dois critérios para identificar o conhecimento: a historicidade de sua produção, bem como as possibilidades de explicar a realidade em suas determinações.

Concordamos com Magalhães (2016, p. 74) ao afirmar que

[...] a análise do desenvolvimento da atividade da criança vislumbra orientar o professor quanto à estrutura da atividade e ao desenvolvimento das funções psíquicas, conteúdos que estão implícitos nos princípios para a organização do ensino [...] e que devem ser avaliados constantemente no desenvolvimento global da 
criança, a fim de que possamos orientar tal desenvolvimento em sua melhor direção. Se é o ensino que promove o desenvolvimento por meio da correta organização da aprendizagem da criança, então é a avaliação desse desenvolvimento que nos permite o acesso a tal ensino, que não está aparente na relação, mas que está contido no desenvolvimento da criança.

Procurando sinalizar para atuação do professor, os conteúdos de ensino bem como as melhores formas de sua sistematização, trazemos as colocações de Martins (2012) que tratam sobre a natureza das ações educativas que devem ser realizadas com as crianças. De acordo com a autora, o professor necessita dominar conhecimentos que intervenham de forma indireta e direta no desenvolvimento da criança, constituindo-se como elementos mediadores da atividade docente, interferindo de forma qualitativa no desenvolvimento da criança.

Os conteúdos indiretos são apresentados por Martins como "conteúdos de formação operacional", sendo compreendidos como "[...] os saberes interdisciplinares que devem estar sob domínio do professor e subjacentes às atividades disponibilizadas aos alunos" (MARTINS, 2012, p. 95). Eles se constituem como conhecimentos no âmbito dos saberes pedagógico, sociológico, psicológico, dentre outros e não serão transmitidos às crianças em seu conteúdo conceitual, mas são promotores, daquilo que a autora denomina "aprendizagem indireta". Ao serem disponibilizados para a criança, estes conteúdos operacionais

[...] incidem na propulsão do desenvolvimento de novos domínios psicofísicos e sociais expressos em habilidades específicas constitutivas da criança como ser histórico social, a exemplo de: autocuidados; hábitos alimentares saudáveis; destreza psicomotora; acuidade perceptiva e sensorial; habilidades de comunicação significada; identificação de emoções e sentimentos; vivencia grupal dentre outras. À luz desses saberes, a criança desenvolve propriedades e constrói conhecimentos empíricos na centralidade das operações e ações que executa conquistando, progressivamente, formas culturais elaboradas de funcionamento (MARTNS, 2012, p. 95-96).

Já os conhecimentos que possuem interferência direta no desenvolvimento das crianças, Martins (2012, p. 96) denominou de conteúdos de formação teórica, sendo aqueles que "[...] compreendem os domínios das várias áreas do saber científico, transpostos sob a forma de saberes escolares". Tais conteúdos,

[...] permearão as atividades propostas às crianças tendo em vista sua socialização como tal, isto é, para que se efetivem como objetos de apropriação, devem ser 
transmitidos direta e sistematizadamente em seus conteúdos conceituais e, para tanto, precisam ser ensinados. Tais conhecimentos corroboram para aquisições culturais mais elaboradas, tendo em vista a superação gradual de conhecimentos sincréticos e espontâneos em direção à apropriação teórico-prática do patrimônio intelectual da humanidade (MARTINS, 2012, p. 96).

Destaca ainda a autora que os conteúdos de formação operacional interferem diretamente na constituição de novas habilidades na criança, mobilizam os processos psicológicos elementares, atuando nas funções inatas, complexificando sua estrutura e as formas de funcionamento, transformando-as em funções psicológicas superiores. Ao instrumentalizar a criança com ações que possibilitam conhecer os objetos a sua volta, desempenham uma influência indireta na construção de conceitos. Em contrapartida, os conhecimentos teóricos operam indiretamente no desenvolvimento das funções psicológicas na medida em que promovem a apropriação dos conhecimentos, dos conceitos. Martins (2012, p. 97) afirma, portanto que por isso

[...] jamais os conteúdos teóricos a serem ensinados [podem] ser selecionados sob a ótica simplista e pragmática circunscrita à sua utilização imediata. Tais conteúdos, atuando diretamente na elaboração de conceitos, operam indiretamente no desenvolvimento das funções afetivo-cognitivas.

Evidencia-se deste modo que, os conteúdos operacionais e teóricos atuam dialeticamente, devendo ambos ser contemplados na organização da prática pedagógica. Assim, é preciso que "[...] as ações educativas contemplem de forma integrada os conteúdos de formação operacional e de formação teórica em consonância com os períodos de desenvolvimento da criança" (MARSIGLIA; SACCOMANI, 2016, p. 352).

Cabe ainda uma observação sobre a avaliação da aprendizagem enquanto atividade mediadora no interior da prática educativa, sinalizando que nela ocorrem dois momentos específicos que se imbricam: além de promover o desenvolvimento intrapsíquico da criança, ao favorecer a reorganização do ensino, contribui também no plano interpsíquico, à medida que envolve o trabalho docente em uma totalidade e o qualifica cada vez mais. A avaliação ocorre assim em um duplo trânsito: oferece possibilidades de organização de ações desenvolventes tanto no plano das ações coletivas quanto individual e requalifica todo o conjunto. 
A partir deste movimento, faz-se necessário que o professor esteja atento às formas de execução das atividades proporcionadas ao aluno, de modo a redirecionar, quando for o caso, suas ações pedagógicas. Dessa forma, poderá perceber se o ensino está incidindo, ou não, sobre a área de desenvolvimento iminente da criança. Evidenciar a avaliação como atividade mediadora entre a atividade de ensino e a atividade de aprendizagem, constitui-se como possibilidade de materializar o objeto da educação, ou seja, produção da humanidade dos sujeitos por meio da apropriação das objetivações humanas.

No próximo item procuraremos sinalizar, no âmbito do método pedagógico, elementos para a avaliação da aprendizagem na educação infantil. Não queremos com tal discussão reduzir o método pedagógico a uma metodologia de ensino, mas justamente contribuir com a defesa da necessidade de que o entendimento teórico-pedagógico encerra uma compreensão teórico-metodológica da prática pedagógica.

\section{Avaliação da aprendizagem como mediação na prática pedagógica histórico-crítica}

No tópico anterior, procuramos sinalizar as intermediações entre pedagogia históricocrítica e psicologia histórico-cultural a partir da relação dialética entre ensino, avaliação e aprendizagem. Neste tópico procuraremos explicitar o movimento do método pedagógico, organizado por Saviani, entendendo-o na qualidade de momentos interdependentes e articulados, que ultrapassam

[...] o âmbito da didática, não havendo uma correspondência linear entre eles e a organização dos tempos e conteúdos constitutivos da aula em si, ou seja, consideramos que a conversão dos referidos passos em procedimentos de ensino encerra o risco de culmina numa leitura reducionista em relação às proposições do autor (MARTINS, 2013, p. 289).

Nossa defesa é de que a sistematização do método pedagógico explicita elementos centrais para a organização do trabalho educativo, orientando-se dialeticamente para a formação e transformação dos indivíduos. Entendemos, com base na pedagogia históricocrítica, que é possível oportunizar aos sujeitos ultrapassar o conhecimento imediato do fenômeno por meio dos conceitos teóricos, produzindo formas de pensamento que 
qualifiquem esta relação, entendendo-a não de forma caótica e desconexa, mas sim como síntese de determinações diversas. Martins (2016, p. 26, grifo nosso) evidencia que

[...] não obstante o autor ter organizado a exposição desse método em cinco momentos - prática social, problematização, instrumentalização, catarse e prática social (requalificada) -, há que se destacar esses que não são procedimentos didáticos. Na qualidade de conceitos metodológicos, tais momentos são abstrações do pensamento a orientarem as ações concretas na realidade.

Esse excerto torna-se necessário para não compreendermos a pedagogia históricocrítica de maneira didatizada, organizada em momentos estanques, lineares, pois isso descaracteriza todo seu arcabouço teórico-metodológico, que se assenta no método materialista histórico-dialético, proposto por Marx, esvaziando-a, transformando-a em "[...] quase um receituário, que em lugar de oportunizar o avanço da escola, só a reforça como farsa" (LAVOURA; MARSIGLIA, 2015, p. 348). Diante destas considerações, nosso intuito será explicitar os momentos do método e articulações destes à dinâmica entre aprendizagem, ensino e avaliação. Destarte, os momentos do método pedagógico só podem ser entendidos nessa dinâmica como atividades que, possuem especificidades e ao mesmo tempo constituemse como interdependentes.

O ponto de partida da prática educativa corresponde à prática social. Nesta relação, professor e aluno se posicionam de formas distintas: enquanto o professor possui uma visão mais sintética da prática social, a compreensão dos alunos manifesta-se de forma sincrética. Martins (2016, p. 28) ressalta que, a prática social do professor será sintética, conforme os conhecimentos que este possui a respeito dela, mas esta síntese ainda é precária tendo em vista que "[...] do ponto de partida, desconhece a parcela da realidade que irá dispor como seus alunos".

No que se refere ao aluno, sua compreensão da prática social é sincrética, tendo em vista que, por mais experiências e conhecimentos que detenha, sua condição de aluno, impossibilita que articule a experiência escolar produzida pela prática pedagógica e suas experiências sociais, superando-as. Nesta direção, como afirma Martins (2016, p. 28)

[...] o educando ainda não dispõe de elementos que lhe possibilitem a identificação das articulações entre a sua escolarização e a decodificação concreta do real. Tais articulações, por sua vez, impõem-se como objetivos da própria prática pedagógica, o que coloca na decisiva dependência da qualidade com a qual ela se realiza. 
Saviani (2016) destaca a necessidade de o trabalho pedagógico possibilitar, desde a educação infantil, o desenvolvimento do sujeito tomando como premissa a apropriação das objetivações humanas, tendo em vista que elas, pelo movimento de abstração, favorecem a organização de formas conscientes e mediadas de se relacionar com a realidade. Nesta perspectiva,

[...] dizer, então, que o professor, para atuar eficazmente junto aos alunos deve ter uma compreensão sintética da prática social significa dizer que ele deverá ter uma compreensão articulada das múltiplas determinações que caracterizam a sociedade. Ou seja, se os alunos, situando-se no ponto de partida numa visão sincrética têm uma compreensão ainda superficial marcada pelas vivências empíricas presas às impressões imediatas, o professor já teria passado pela análise, pela mediação do abstrato, ascendendo a uma compreensão concreta, isto é, apreendendo a realidade como síntese de múltiplas determinações (SAVIANI, 2016, p. 22).

Dito isto, é preciso estabelecer as relações entre a atividade de aprendizagem e a atividade de ensino, uma vez que as ações dos sujeitos (professor e aluno) se conduzem "[...] por percursos lógicos e conteúdos simbólicos diferentes e necessariamente contraditórios" (MARTINS, 2016, p. 28).

O percurso da aprendizagem vai do concreto para o abstrato, do cotidiano para o nãocotidiano, colocando o aluno na condição de aprendiz. O estudante caminha na direção do ordenamento da imagem subjetiva sobre a realidade, de modo que supere as captações imediatas que se encontram circunscritas às suas experiências, tendo em vista que "[...] na ausência de mediações cada vez mais abstratas, subjuga-se à apreensão do objeto em suas manifestações fenomênicas" (MARTINS, 2016, p. 29). Inversamente, o percurso do ensino vai do abstrato para o concreto, do não-cotidiano para o cotidiano. Significa dizer que "[...] o ensino só pode sustentar-se como objetivação das apropriações realizadas por quem ensina" (MARTINS, 2016, p. 29). Nesta relação, a escolarização coloca-se como possibilidade no desenvolvimento das capacidades de abstração.

No âmbito da relação entre aprendizagem e ensino, a avaliação se situa, a partir da compreensão do movimento contraditório de ambas as atividades, favorecendo a identificação dos elementos específicos de cada uma, de modo que a organização de ações e operações possibilitem a organização do trabalho pedagógico, detectando as questões que precisam ser resolvidas no âmbito da prática pedagógica. Temos aqui a problematização, como momento 
que, não se encerra em si mesmo, mas no qual “[...] reside a definição de quais sejam os objetivos educacionais pretendidos e quais as ações se fazem necessárias para a sua consecução" (MARTINS, 2016, p. 30).

Se por meio da problematização identificamos as questões que precisam ser solucionadas no âmbito da prática social, se expressa, portanto, a necessidade de organizar a instrumentalização que possibilite a apropriação dos conhecimentos teóricos necessários para responder aos problemas da prática social. Martins (2016, p. 30) salienta que

[...] o domínio do conhecimento científico a ser transmitido e os conceitos
que se pretende ensinar são ferramentas imprescindíveis para que o professor
opere com e por meio delas de maneira prática, sintonizada, se for o caso,
para a concreticidade e empiria do pensamento infantil sem, contudo, deixar-
se aprisionar-se por elas. Para tanto, ele precisa ter superado o sincretismo de
seu próprio pensamento, precisa dispor de objetivações a serem apropriadas
pelo aluno, criar tensões problematizadora que impulsionem transformações
psíquicas, e tudo isso porque entre iguais ou quase iguais não se instalam
contradições que movam o desenvolvimento.

Tomando como referência a instrumentalização dos sujeitos, é preciso identificar quem é o sujeito que aprende, entendendo-o como aquele que sintetiza a história das apropriações que lhe foram disponibilizadas. A relação conteúdo-forma, pressupõe a necessidade de um destinatário, exigindo compreender: quem é o aluno? Que conteúdos podem possibilitar o seu desenvolvimento? Com quais finalidades? Quais as melhores formas? As ações e operações planejadas estão incidindo sobre seu desenvolvimento? De que maneira? Neste movimento, a avaliação institui-se como a possibilidade de refletir sobre o desenvolvimento das ações necessárias para que a apropriação das objetivações se efetive, bem como no encaminhamento daquilo que ainda irá se consolidar.

Tais questionamentos só serão possíveis se o professor compreender que para promover o desenvolvimento deverá identificar aquilo que já está consolidado, para assim agir sobre aqueles aspectos que estão em iminência. O nível de desenvolvimento real da criança e a área de desenvolvimento iminente ajudam a organizar o ensino e incidir sobre a aprendizagem.

A psicologia histórico-cultural fornece contribuições relevantes para a organização do ensino e da aprendizagem ao se debruçar sobre a periodização do desenvolvimento à luz do conceito de atividade-guia, como aquela que promoverá o maior alcance de desenvolvimento 
do sujeito em determinadas condições de vida e educação, tendo em vista que a nossa relação com a realidade ocorre de forma única em cada momento da vida, e possui especificidades que incidem diretamente na formação de nossa personalidade.

Martins (2016, p. 30) destaca que "[...] a instrumentalização do trabalho pedagógico pressupõe as condições teórico-metodológicas para a operacionalização do "duplo trânsito" requerido ao bom ensino: do abstrato ao concreto e do concreto ao abstrato". À medida que a criança se apropria dos instrumentos teóricos e práticos, ocorrem mudanças significativas no desenvolvimento de suas funções psicológicas, consolidando uma nova maneira de se relacionar com a realidade. Este momento, denominado como catarse, representa a efetiva incorporação dos instrumentos culturais, produzindo reorganização nos processos psíquicos da criança, bem como novas formas de captar a realidade. Como assevera Martins (2016, p. 31) “[...] a catarse implica rupturas e saltos qualitativos- gera transformação! Trata-se, então, da efetivação da intencionalidade educativa condensada na conquista por parte de cada aluno singular "da humanidade produzida pelo conjunto dos homens". Por meio deste movimento, fica compreendido que a devida organização da atividade de ensino, possibilita a efetivação da atividade de aprendizagem, contribuindo com a

[...] superação das representações primarias dos objetos e fenômenos em direção à sua representação conceitual, para a superação dos domínios cotidianos e dos pseudoconceitos em direção ao pensamento conceitual, para o desenvolvimento da complexa capacidade culturalmente formada que, usualmente, chamamos de capacidade para pensar além das aparências. (MARTINS, 2013, p. 295-296).

Tornar o real inteligível pressupõe a apropriação de produções humanas construídas historicamente. E esta não se dá de forma direta, mas por meio da organização de processos mediados. Deste movimento, desdobra-se uma nova relação com a prática social, agora diferente daquela no ponto de partida. Saviani (2008, p. 58) destaca que

[...] a prática social referida no ponto de partida (primeiro passo $^{1}$ ) e no ponto de chegada (quinto passo) é e não é a mesma. É a mesma, uma vez que é ela própria

\footnotetext{
${ }^{1}$ Cabe destacar que Saviani ao sistematizar o método pedagógico da pedagogia histórico-crítica em cinco passos, não os caracteriza como procedimentos didáticos, mas, na "[...] qualidade de conceitos metodológicos, tais momentos são abstrações do pensamento a orientarem as ações concretas na realidade" (MARTINS, 2016, p. 26). Fundamentando-se no método marxista, Martins destaca que o autor procura ao desenvolver sua proposta pedagógica, evidenciar os momentos do método no processo de construção do conhecimento, a saber: "[...] a
} 
que constitui ao mesmo tempo o suporte e o contexto, o pressuposto e o alvo, o fundamento e a finalidade da prática pedagógica. E não é a mesma, se considerarmos que o modo de nos situarmos em seu interior se alterou qualitativamente pela mediação da ação pedagógica; e já que somos, enquanto agentes sociais, elementos objetivamente constitutivos da prática social, é licito concluir que a própria prática se alterou qualitativamente.

O momento catártico modifica a relação do sujeito com a realidade pela mediação das apropriações dos conhecimentos teóricos, favorecendo uma mudança na relação deste com a realidade. Como destaca Saviani (2008, p. 58) “[...] ao mesmo tempo que os alunos ascendem ao nível sintético em que, por suposto, já se encontrava o professor no ponto de partida, reduz-se a precariedade da síntese do professor, cuja compreensão se torna mais e mais orgânica".

Entendemos que a pedagogia histórico-crítica representa a teoria pedagógica mais rica em elementos que permite compreender o trabalho pedagógico como constituído pelos movimentos entre aprendizagem, ensino e avaliação, bem como possibilita compreender os movimentos contraditórios desta relação. Torna-se necessário evidenciar, mais uma vez, o caráter dialético do processo educativo, bem como do método proposto por esta teoria, de modo que "[...] não se trata de uma relação mecânica entre os passos do método que determinaria que primeiro se realizaria o passo da problematização, depois a instrumentalização e, no momento seguinte, a catarse. Na verdade, esses momentos se imbricam" (SAVIANI, 2016, p. 37).

Aqui cabe retomar a questão da avaliação da aprendizagem, de modo a compreendê-la como atividade mediadora entre as atividades de ensino e aprendizagem à luz do método pedagógico. No âmbito da prática educativa, entendendo-a como modalidade da prática social, despontam a atividade de ensino, que tem como sujeito o professor, e a aprendizagem, que tem como sujeito o aluno, ocupando lugares distintos no seu interior.

A avaliação se situa como atividade mediadora no interior da prática educativa, à medida que compreende seu movimento de contradição interna e possibilita, por meio da problematização, da instrumentalização e da catarse, o acesso aos conhecimentos que promovem o desenvolvimento, gerando mudanças significativas na relação do sujeito com a

captação empírica e sincrética da realidade como ponto de partida, as mediações abstratas do pensamento como possibilidades para superação dessa condição, tendo em vista a apreensão concreta da realidade como síntese de múltiplas determinações" (MARTINS, 2016, p. 27). 
realidade. Ela constitui-se como atividade mediadora porque se interpõe entre ensino e aprendizagem, favorecendo a promoção de mudanças significativas no desenvolvimento humano, possibilitando a organização de processos de ensino que desencadeiam situações de aprendizagem, elevando a formação do sujeito a um novo nível de desenvolvimento.

\section{Considerações finais}

Neste artigo, procuramos evidenciar as contribuições da pedagogia histórico-crítica e da psicologia histórico-cultural para a organização de processos avaliativos na educação infantil. Na atualidade, a escola constitui-se como o espaço institucionalizado para a socialização do saber sistematizado, oriundo de esferas filosóficas, artísticas, científicas. Ocorre que em uma sociedade marcada pelas relações de classe, a escola reserva aos sujeitos distintas possibilidades de humanização, razão que sustenta nossa afirmação da escola como lócus da apropriação dos conhecimentos por todos os indivíduos. Nela, o professor tem como legítima a função de organizar a atividade de ensino que permita a compreensão da realidade e sua transformação.

A avaliação, de acordo com nossa perspectiva teórica, situa-se como atividade mediadora no interior da prática educativa, que contribui para a organização de novos processos de ensino que desencadearão novas situações de aprendizagem.

Afirmar que a educação escolar, desde a educação infantil, deve favorecer o desenvolvimento humano em suas máximas expressões, em um contexto social que se sustenta a partir da exploração de uma classe e aliena o sujeito de si e dos outros, não é algo que nos imobiliza; ao contrário, instiga-nos a lutar para que a escola possa cumprir a sua função social, garantir o acesso dos filhos da classe trabalhadora ao patrimônio humanogenérico. Além disso, é preciso lutar pela qualidade da escola. É mais do que urgente o fortalecimento da educação escolar para superar o obscurantismo, a exploração de seres humanos por outros seres humanos e a desumanização dos indivíduos que resulta da sociedade de classes. 


\section{Referências}

CASTRO, T. P. Avaliação da aprendizagem à luz da pedagogia histórico-crítica: contribuições para a formação de professores. 2017. Dissertação (Mestrado em Educação), Universidade Federal do Espírito Santo. Vitória, 2017.

DUARTE, N. A individualidade para si: contribuição a uma teoria histórico-crítica da formação do indivíduo. 3 ed. Campinas, SP: Autores Associados, 2013.

DUARTE, N. Vigotski e o "aprender a aprender": crítica às apropriações neoliberais e pósmodernas da teoria vigotskiana. 5 ed. Campinas, SP: Autores Associados, 2011.

LAVOURA, T.; MARSIGLIA, A. C. G. A pedagogia histórico-crítica e a defesa da transmissão do saber elaborado: apontamentos acerca do método pedagógico. IN: Perspectiva, Florianópolis, v. 33, n. 1, jan/abr. 2015, p. 345-376.

LEONTIEV, A. Uma contribuição à teoria do desenvolvimento da psique infantil. In: VIGOTSKII, L. S.; LURIA, A. R. Linguagem, desenvolvimento e aprendizagem. São Paulo: Ícone, 2006, p. 59-84.

MAGALHÃES, G. M. Análise da atividade-guia da criança na Primeira Infância: contribuições da psicologia histórico-cultural para a avaliação do desenvolvimento infantil dentro de instituições de ensino. 2016. Tese (Doutorado em Educação Escolar). Faculdade de Ciências e Letras, Universidade Estadual Paulista Júlio de Mesquita Filho. São Paulo, 2016.

MARSIGLIA, A. C. G; SACCOMANI, M. C. S. Contribuições da periodização históricocultural do desenvolvimento para o trabalho pedagógico histórico-crítico. IN: MARTINS, L. M.; ABRANTES, A. A.; FACCI, M. G. D. (Org.). Periodização histórico-cultural do desenvolvimento psíquico: do nascimento à velhice. Campinas, SP: Autores Associados, 2016, p. 343-368.

MARTINS, L. M. Psicologia histórico-cultural, pedagogia histórico-critica e desenvolvimento humano. IN: MARTINS, L. M.; ABRANTES, A. A.; FACCI, M. G. D. (Org.) Periodização histórico-cultural do desenvolvimento psíquico: do nascimento à velhice. Campinas, SP: Autores Associados, 2016, p. 13-34.

MARTINS, L. M. O desenvolvimento do psiquismo e a educação escolar: contribuições à luz da psicologia histórico-cultural e da pedagogia histórico-crítica. Campinas: Autores Associados, 2013.

MARTINS, L. M. O ensino e o desenvolvimento da criança de zero a três anos. IN: ARCE. A.; MARTINS, L. M (org.). Ensinando aos pequenos de zero a três anos. Campinas, SP: Editora Alínea, 2012, p. 93-121.

MORAES, S. P. G. Avaliação do processo de ensino e aprendizagem em matemática: contribuições da teoria histórico-cultural. Tese (Doutorado em Ensino de Ciências e Matemática) - Universidade de São Paulo, São Paulo, 2008. 
147 Polyphonía, v. 32/2, jul./dez. 2021

SAVIANI, D. A pedagogia histórico-crítica na educação do campo. IN: BASSO, J. D.; NETO, J. L. S.; BEZERRA, M. C. S. Pedagogia histórico-crítica e educação no campo: história, desafios e perspectivas atuais. São Carlos: Pedro \& João Editores e Navegando, 2016, p. 16-43.

SAVIANI, D. Pedagogia histórico-crítica: primeiras aproximações. 11 ed. Campinas, SP: Autores Associados, 2013.

SAVIANI, D. Escola e democracia. Campinas, SP: Autores Associados, 2008. 